Int. J. Electrochem. Sci., 14 (2019) $5820-5830$

International Journal of

ELECTROCHEMICAL

SCIENCE

$\underline{\text { www.electrochemsci.org }}$

\title{
A Cheap Polypyrrole-Derived Fe-N-C Electrocatalyst with Ultrahigh Oxygen Reduction Activity in Alkaline Electrolyte
}

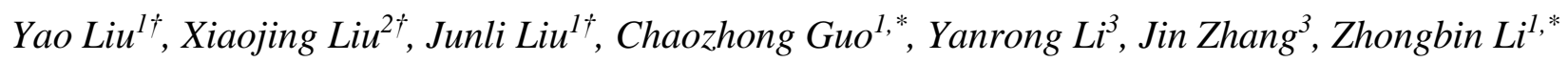 \\ ${ }^{1}$ Research Institute for New Materials Technology, School of Materials and Chemical Engineering, \\ Engineering Research Center of New Energy Storage Devices and Applications, Chongqing University \\ of Arts and Sciences, Chongqing 402160, China. \\ ${ }^{2}$ Ningbo Key Laboratory of Specialty Polymers, Faculty of Materials Science and Chemical \\ Engineering, Ningbo University, Ningbo 315211, China \\ ${ }^{3}$ College of Materials Science and Engineering, Chongqing University of Technology, Chongqing \\ 400054, China \\ ${ }^{\dagger}$ These authors equally contributed to this work, and they are considered as the co-first author. \\ *E-mail: guochaozhong1987@163.com (C. Guo); las1166@ hotmail.com (Z. Li)
}

doi: $10.20964 / 2019.06 .76$

Received: 2 October 2018 / Accepted: 1 April 2019 / Published: 10 May 2019

Ternary Fe-N-C catalysts are regarded as the most promising candidates for low-cost alternatives to the Pt-based materials for catalyzing the oxygen reduction reaction (ORR). In this paper, the $\mathrm{Fe}$ and $\mathrm{N}$ codoped carbon catalyst (Fe-Py@K-800) with the unique foam-like 3D structure has been fabricated by using the molecular sieve as a new solid-state template. The results of physical characterization indicate that $\mathrm{Fe}$ atoms are coordinated with nitrogen atoms to form the Fe-N ORR-active structure. In contrast with the commercial Pt/C catalyst, the Fe-Py@K-800 displays a comparable ORR electrocatalytic activity with an onset potential of $\sim 1.1 \mathrm{~V}$ and a half-wave potential of $\sim 0.88 \mathrm{~V}$ ( $v s$. RHE), however, the long-term stability of Fe-Py@K-800 is obviously better. These results show that iron-organic coordination in the pyrrole ring will play a role in the generation of nitrogen-rich active sites, which facilitates the enhancement of ORR activity in alkaline electrolyte.

Keywords: Porous carbon, Oxygen reduction, Electrocatalyst, Molecular sieve

\section{$\underline{\text { FULL TEXT }}$}

(C) 2019 The Authors. Published by ESG (www.electrochemsci.org). This article is an open access article distributed under the terms and conditions of the Creative Commons Attribution license (http://creativecommons.org/licenses/by/4.0/). 